\title{
ProMe: A Mentoring Platform for Older Adults Using Machine Learning Techniques for Supporting the "Live and Learn" Concept
}

\author{
Giorgos Kostopoulos, ${ }^{1}$ Katja Neureiter, ${ }^{2}$ Dragos Papatoiu, ${ }^{3}$ Manfred Tscheligi, ${ }^{4}$ \\ and Christos Chrysoulas $\mathbb{1 0}^{5}$ \\ ${ }^{1}$ Gluk Advice B. V., Maastricht, Netherlands \\ ${ }^{2}$ AIT Austrian Institute of Technology GmbH, Seibersdorf, Austria \\ ${ }^{3}$ Siveco SRL, București, Romania \\ ${ }^{4}$ Center for Human-Computer Interaction, University of Salzburg, Salzburg, Austria \\ ${ }^{5}$ Computer Science \& Informatics Dep., London South Bank University, London, UK
}

Correspondence should be addressed to Christos Chrysoulas; chrysouc@lsbu.ac.uk

Received 25 June 2018; Accepted 11 November 2018; Published 2 December 2018

Guest Editor: Giovanna Sannino

Copyright (C) 2018 Giorgos Kostopoulos et al. This is an open access article distributed under the Creative Commons Attribution License, which permits unrestricted use, distribution, and reproduction in any medium, provided the original work is properly cited.

\begin{abstract}
It is well known what an important role employment plays in our lives and how it influences our everyday life. With the help of employment, all of us as individuals manage to create our personal and social net that not only gives meaning and financial security but also heavily affects our social status, contributes to self-esteem, and plays a vital role on the way our social relationships at work and (not only) are formed. Being work active even after the retirement time has been found to have mostly useful and positive effects. Age groups that are in the after retirement age group (65 and more) and keep working can significantly improve their mental health since they feel that there are still things to offer to others. ProMe aims to provide a unique framework for the people being in this transitional phase of their life, from work to retirement, thus playing a vital role in supporting their mental health and well-being. ProMe provides a platform for the younger generation to benefit from the accumulated professional and formal knowledge and experience of the older. In this way, ProMe supports professional intergenerational cooperation and mentoring, bringing together older adults with younger generations.
\end{abstract}

\section{Introduction}

Employment offers an opportunity to use one's skills and experience and to maintain social contacts beyond retirement, enhancing self-esteem by providing one's expertise to and for others. Activities such as voluntary work (e.g., helping others) and programs that bridge employment and retirement (i.e., any kind of paid occupation between a person's career and the withdrawal from labor force) have been shown to enhance one's well-being and quality of live. The effects of demographic aging show that constant decrease on the share of people of working age compared to an increasing relative number of those who are retired. This demographic shift requires society to reconsider the role older adults' play in a society, even after retirement. In the Organisation for Economic Co-operation and Development (OECD) countries, it is common for workers to take early retirement, leaving the labor market before the standard pension eligibility age. This, in turn, leads to an increasing number of economically inactive people relative to those who are economically active. ProMe [1] aims to change perceptions on aging and the vocational activities of older adults. It offers an innovative solution that is designed to serve intergenerational dialogue, lifelong learning, and, on top of those, creating value among generations. It will also play a vital role on the mental health of the elderly since there are numerous studies specifically pointing out the importance of work in the elderly (after retirement) [2-7]. 
Based on these reflections, ProMe aims in providing meaningful work opportunities in the life of older adults, in order to smoothly pass from work to retirement and what after that. During their working life (or no), adults accumulated a lot of knowledge in domains related with their work and beyond. Our vision is to harness this and to achieve professional intergenerational cooperation and mentoring via our proposed platform, bringing together older adults with younger generations. Especially in the work context, mentoring is considered a valuable approach, e.g., to enhance the diffusion of expert knowledge within a working group or an organisation.

ProMe is based on theoretical concepts for mentoring $[8,9]$. modern (professional) social networks (e.g., Xing, ResearchGate, and LinkedIn) try to promote strengthening social relations among people who share interests and activities though their mechanisms. Apart form the above, ProMe offers the opportunity for older adults' meaningful occupation on a voluntary basis through taking an active role as a mentor. This is feasible by encouraging them to share their knowledge and experience with younger generations who are eager to learn, trying to include the ones that not only seeking a career but also a more general life advice.

Through ProMe, older adults will be able to continue working thus allowing them to be and play an active role in social and working life, even after their retirement. In this way, added value for the society and economy is created. We consider mentoring as "walking alongside" a person-sharing expertise, values, and skills. It entails informal communication, including voluntary engagement, mutual respect, shared responsibility, and empowerment of the mentee, resulting in a mutually beneficial relationship. It can be described as a process for the informal transmission of knowledge, ranging from accompanying a person over a longer period (e.g., preparing a project or settling in a new company) to simply providing advice or information regarding specific topics (e.g., when applying for a new job).

ProMe provides an effective way of bringing together people in a long term and effectively relationship they need for developing a shared and transparent psychological contract they both commit to. "The term psychological contract is used to describe a set of individual beliefs or set of assumptions about promises voluntarily given and accepted in the context of a voluntary exchange relationship between two or more parties" [10]. "Psychological contract theory suggests that we shift the focus from what one expects to gain from the relationship to what one feels he or she is obligated to provide in the relationship. (...) understanding these obligations might provide valuable insight into why some specific functions are provided and others are not, especially with regard to structural characteristics of the relationship, such as the level of formality" [9]. In such collaborative relationships, you have two and sometimes even more, if we are talking for instance for a learning network multiple, psychological contracts: a psychological mentoring contract of a "requester of support" contains the obligations each of the involving parts owe each other [11]. For an effective collaborative relationship, it is important that both psychological contracts are compatible and preferably transparent for both parties (so forming a shared contract). Even though, a possible lack of agreement on the mutual obligations does not mean that there is no psychological contract. An important point to remember is that psychological contracts are conceptualized as an individual's perceptions of mutual obligations and that actual agreement on the contract terms is not a requirement for a psychological contract to exist [12]. There is the possibility for an individual to form a type of psychological contract with someone he/she considers to be a supporter (or protégé) without the other party to develop a similar psychological contract with them. In this scenario, there is the possibility that the collaborative relationship will not be productive and long lasting [11]. Associated with the promises each party makes with another are mutual obligations and expectations, and depending on each party's beliefs about these promises, a psychological contract is subject to variations in expectations about that contract, i.e., matches and mismatches [13], which may affect the potential for each party's expectations being met. If beliefs and assumptions and their underlying promises are clear for all involved parties, it is more likely the expectations will be met. We highly believe that valid "information" about what each part expects and what to be expected of them, as they get involved in one of the three collaborative relationships, will play a vital role to the quality and the sustainability of that collaborative relationship.

Based on these considerations and the pivotal role of mentoring, the ProMe framework/platform is supporting different opportunities for informal communication through a number of functionalities, like video/text-chat, email, blogs, and forums. Apart from the aforementioned means of informal communication, ProMe provides potential-end users with the opportunity to take over different kinds of "mentoring roles." Recognizing the diverse aspects of mentoring, different types/roles of mentors and mentees, have been considered based on someone's experience (please also check Section 4, regarding the system architecture).

The remainder of this paper is organized as follows. Section 2 surveys related work in the area. Section 3 presents a representative use case of the proposed framework. Section 4 provides an insight on the internal architecture of the system. In Section 5, the proposed recommendation system is presented, while Section 6 concludes the paper and provides future directions.

\section{State of the Art}

There are numerous web-based platforms currently available that aim to match and guide mentors and protégés, for example, connecting graduates with a mentor to contemplate on one's career or to support students to achieve their goals. Most of these services also have partnerships, with colleges, universities, or professional societies to increase resources at a local level and expand mentoring programming and opportunities. In contrast to these solutions, ProMe does not only provide an opportunity to match mentor and mentee, but facilitates contact by means of the different functionalities (e.g., video conferencing and text 
chat) that are offered via the platform on different devices. It provides a flexible communication environment and allows mentoring independent of time and space, which is currently only realized by a small number of online e-mentoring services, like Horsesmouth [14] and Senior Engage [15].

The Aware [16] project proposes a telematics platform for older adults to prepare them for the transition to retirement by allowing sharing knowledge to maintain an active role after retirement. It also provides a training module to acquire expertise in using information and communication technologies (ICTs) and services over Internet. ProMe approach offers different opportunities for maintaining meaningful occupation not only in the transition to retirement but also beyond. Besides sharing knowledge ProMe aims at supporting intergenerational learning so that both, older adults and younger generations, benefit from the solution.

E-mentoring [17] provides Internet-based education, social, and corporate email-based mentoring, while ProMe provides a variety of different mentor roles (according to users' capabilities) and suitable communication opportunities for the mentor and the mentee (e.g., text/video-chat, forum, and blog).

The Hear Me [18] project connects retirees with young adults who have not completed their secondary education and lack the qualifications for meaningful employment. Also provides cognitive and practical education for older adults to become mentors for youths at risk. Our approach not only focuses on a specific group of mentees but also addresses interested mentees from all generations. ProMe is not intended to be an education tool but considers older adults as competent to get active on the platform, focusing on supporting them to share knowledge and skills.

The Horsemouth [14] project aims in the creation of a public value through the exchange of experiences and knowledge concerning all areas of life (e.g., work and learning). ProMe from the other side focuses on facilitating the exchange of professional knowledge supporting the older adults in continuing and managing an occupational lifestyle.

Horizons Unlimited [19] platform provides mentoring and coaching programs for personal and professional development through matching mentors and mentees. ProMe supports autonomy and independence by allowing older adults to get active as a mentor according to one's own expertise. Tailored specifically to the needs of older adults creates value for the target group by addressing a variety of user experience and acceptance factors (curiosity, motivation, usefulness, accessibility, flexibility, etc.).

The Mentor [20] project aims for young people between the ages of 6 and 18, supports and guides them to build productive and as much as possible meaningful lives, and also matches mentor and mentees. The ProMe approach goes beyond matching mentor and mentee by providing different roles and means of communication. Mentor Net [21] aims at connecting students in engineering and science with mentors in industry. It helps students to achieve their goals through e-mentoring. ProMe encourages mentoring between all age groups. It not only focuses on supporting the mentee but aims at fostering mutually beneficial relationships.
The Senior Engage [15] approach offers an opportunity for retired professionals to share knowledge and experiences with younger professionals to reduce isolation. It uses different means of communication such as video/text chat, and email. The ProMe approach from the other side not only offers an opportunity to exchange knowledge and experiences but also is based on a concept of mentoring, providing a variety of different mentoring roles and continuously supporting the mentoring relationship. It is also worth mentioning that it is not built from scratch and uses existing social structures people are embedded in (e.g., Xing and Linkedin).

\section{Use Case Scenario}

Susan is 58 years old in the transition to her retirement. She has more than thirty years of experience working in a marketing department of a large company and has gained a significant amount of knowledge and expertise throughout the years. Although Susan is looking forward to having more time to spend with her two grandchildren and to pursue her hobbies, she is also thinking about potential opportunities for future occupation to maintain purpose in her life. Susan does not see herself as being an "old person" but as vital and active, and she wants to continue working to some extent, probably on a voluntary basis. Her greatest fear is that she is no longer needed and that all the knowledge she gained throughout the years is lying fallow.

Recently, Susan was invited by her company to give a presentation on marketing strategies based on her knowledge and experience. She enjoyed being involved and would like to continue this kind of activity. At this event, Susan heard about the ProMe platform and its use in sharing professional knowledge with younger generations. She became curious and had a look at the platform. As she could easily access the platform with her LinkedIn account, she logged in and explored the different opportunities and functionalities it provides. She extended her profile, indicating information about her professional knowledge and experience and what kind of mentoring roles she could imagine taking over. The intelligent expert system (agent) provided suggestions for potential mentees, searching for expertise in the area of marketing and she started looking at the several interesting profiles. She did not initially want to take over a specific mentoring role, and she simply started posting some ideas on marketing strategies on the ProMe platform. She obtained interesting feedback from the young students; they were enthusiastic about the blog posts. Following this initial success, she decided to take over the role of a leader after a few weeks. With the easy to use functionalities of the ProMe platform, she started to offer training via video conferencing where she discusses business concepts and ideas with young people. Susan really enjoys it and notices that, in addition to sharing her thoughts and experience, she is also learning new ideas from the young mentees (a two-way process).

Susan wanted to find out more about the different mentoring roles she could become involved with and took the online "Mentor-Check." Apart from her interests, 
expertise, and knowledge she already indicated when extending her profile, the Mentor-Check included questions about the time she could imagine investing being a mentor on the ProMe platform.

The results indicated that she had the skill set required to be the perfect buddy. She really liked the idea of accompanying a younger person, e.g., a marketing graduate starting their first job out of college. Again, the agent supported her in easily finding mentees looking for a mentor in the area she had expertise in. She reviewed the suggested profiles of young people who were searching for a buddy and decided to get in contact with a young woman who was going to start her first big project on her own. They worked together to establish the management concept, using working tools (e.g., calendar to coordinate appointments), concepts, and communication and collaboration tools such as video-chat, email, or Whiteboard, allowing brainstorming together on a first concept. Susan has been working together with her mentee for several months and was perfectly supported by the functionalities provided on the ProMe platform according to the specific needs of this mentoring relationship. Also, after her mentee had successfully started her project, they stayed in contact via the platform for further support in everyday businesses.

\section{System Architecture}

The actual ProMe platform users are considered users with different characteristics on the systems. Figure 1 provides an overview of the different roles in the ProMe system.

(i) Guest/anonymous users: guest/anonymous users are users that can access publicly available sections of the portal without any need for authentication/ authorization. For example, they can have access to the homepage where they can find what the project is about and success stories.

(ii) Registered users: as registered users, we consider those users that have to follow the normal sign-in procedure when trying to access the platform. Registered users are in position to access more personalized (restricted) content and make use the tools that the ProMe platform can offer, based on the role they serve. Three types of registered users exist, considering their roles and attributes in the project. In the scope of the ProMe project, we have identified two types of users: one that acts as a receiver and another that acts as a provider. Those two pairs of user were considered best for the scope of the project in user testing and experts evaluation.

(iii) Provider user: provider users are those users that based on their previous professional experience can choose a suitable role(s) from the list of roles or by doing a "Mentor-check," i.e., based on its profile (expertise, interests, etc.).
(a) Mentor
(b) Advisor

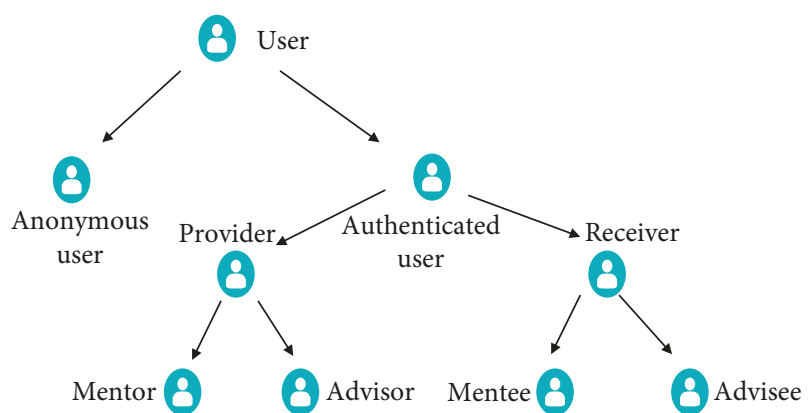

Figure 1: ProMe platform users.

(iv) Receiver user: receiver userhas the role of a participant in the activities initiated by the providers.

\section{(a) Mentee}

(b) Advisee

(v) Administrators: administrators are users that can perform administrative tasks in the system.

The ProMe system is in position to adequately provide users a modern way of communication; thus easily exchange useful learning materials. In Figure 2, we can see all the different levels that the ProMe platform is based on.

Right in the middle and high up, there is the presentation level. The presentation level contains those components needed so as the ProMe platform to be in position to deliver services to the users. These components delivers the graphic interface for the users to access the platform, and platform information that will allow any external systems to gain access to provided services. The described graphical interface is heavily based on up-to-date frameworks like HTML5 or CSS3. Web services are exposed using REST [22].

The service level contains services for implementation of the business flow. The aforementioned set of services can be used by the integration and presentation service blocks in order to provide the needed for the end user functionality. (i) Search in portal: it provides an easy and user friendly way for navigation throughout the platform. (ii) Posting content: it provides an easy way to place/post comments on the forum, and/or there is the option to upload extra educational material. (iii) Creating an account: a new user will be in position to create an account and become a registered user. (iv) Calendar of events: users are in position to organize an event and even invite others. (v) Alerts: a user can make use of the alerts feature so as to receive useful notifications. (vi) Evaluation tests: it provides the option for the users to take by using the platform. (vii) Video conference: the platform users have the opportunity to communicate with each other using audio and/or video means. The suggested solution for the platform, also meeting the identified need, is the BigBlueButton.

External services consist of applications which ProMe uses in order to deliver personalized services to any external users. (i) Web interface: a web interface is considered as the mediator between the actual user and any software that exists on a web server. (ii) Web services: web service is 

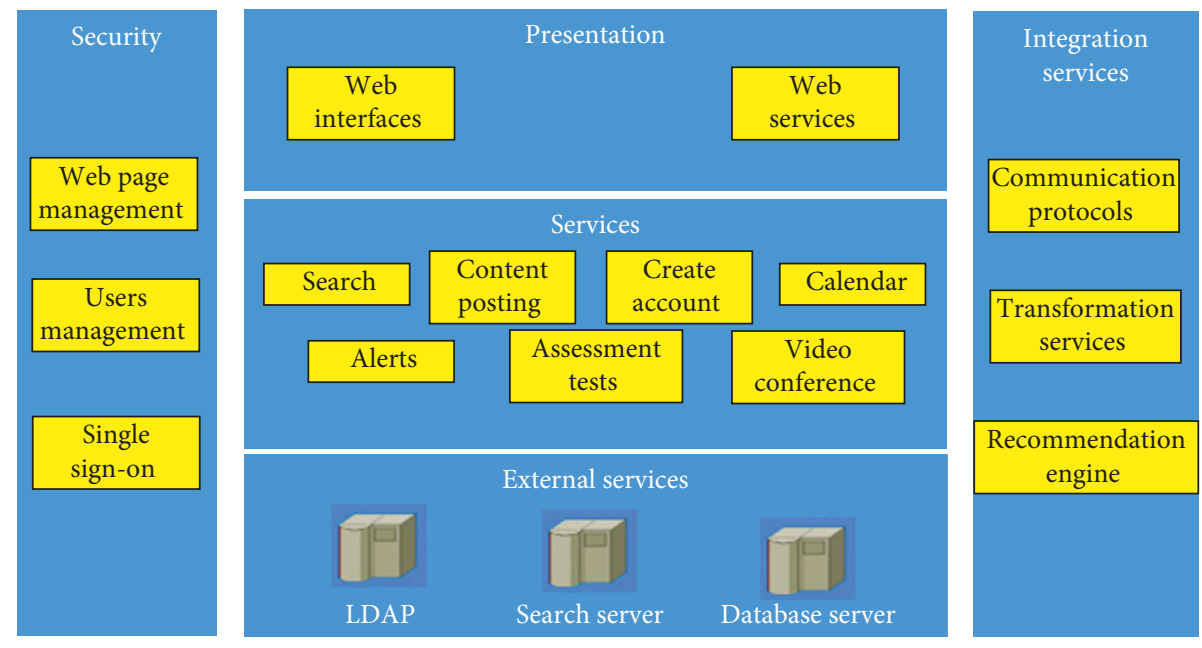

FIgURE 2: System architecture.

considered to be a software system, supporting interoperable machine-to-machine interaction over a network. (iii) Integration services: integration services include all those extra services that the ProMe platform needs to communicate with any external services. (iv) Communications protocol: communication protocols deal with all the exchanging messages. (v) Transformation services: data transformation services (or DTS) is a set of objects and utilities to allow the reading and writing to the system's databases. The subcomponents of the DTS objects are called DTS tools. (vi) Management of web pages: administrators of the systems have the right to manage the content of the web page. (vii) Single sign-on (SSO): Single sign-on is supported thus allowing the users of the platform to make use of the same credentials to access different applications supported by the platform. (viii) Users profile management: it provides the rights for administrators to enable or disable a user account.

\section{Recommendation System}

Building a highly adaptive recommendation system is crucial for our system. The system will be in position to provide recommendations to the users based on historical data, taking into account each user's personal characteristics and needs. Some information about adaptive recommendation systems can be found in [23]. The very basic ingredients for the development of a more precise recommendation system are as follows: trust, similarity, and reputation. When we are talking about trust, what in essence we are trying to capture is the user's trustworthiness. When dealing with similarity, capturing the level of proximity amongst users is the target. And when discussing about reputation, what other users are thinking about a specific use is targeted. A system which can make use of those three ingredients will be in position to provide accurate recommendations about services that someone using the platform is interested for; for example, a user that is in position to give insight to others based on his/her experience. The three aforementioned ingredients can possibly give answers to the next questions. (i) How valid is a review provided by a user? (ii) Can, for example, a mentor address mentee's needs? (iii) What the online community thinks of him/her?

ProMe is in position to provide accurate (to the platform user) recommendations. This is possible by implementing algorithms to adequately cope with the vast amount of data coming from Internet, by implementing customized algorithms for analyzing the incoming data, and by designing and implementing the needed for the user behavior analysis and recommendation algorithms. Figure 3 provides an insight on the abstract architecture/functionality of ProMe's recommendation engine. By simply following the data flow, anyone easily understands the interactions taking place among the various subcomponents. Initially, a user is asking for possible recommendations with the use of a query, which is then passed to the actual recommender component. Based on historical user activities, the recommender component "calculate" the following ingredients: (i) trust, (ii) reputation, and (iii) similarity. Based on the above "calculations," the ProMe platform is in position to provide the end user with the needed recommendations.

Community structure is the base for ProMe's recommendation engine. The central idea of the community structure is that a community can be depicted as a graph. In this graph, users and items are considered to be the nodes, and on the edges, their relationships are placed. In this way, we can easily weight the edges of the graph, and we can also add several features to them, for example, creation time and number of interactions with other nodes.

ProMe is proposing the "walking" across the edges of the graph. So, the level of their trust is in essence the actual length of a walk between two nodes. In the case of no path among two nodes, recommendation can be based on reputations. Figure 4 presents the actual model.

A trust relation from node $i$ to node $j$ indicates how much trust $i$ places in $j$. Considering the recommendation problem in trust networks, such as ProMe, is how can we recommend (predict) a trustworthy mentor (i.e., i) to a mentee (i.e., $j$ ). Let us start with a simple case where all nodes (edges) have the same trust value 1. For example, Figure 5 illustrates a trust network (TN1), which contains the 


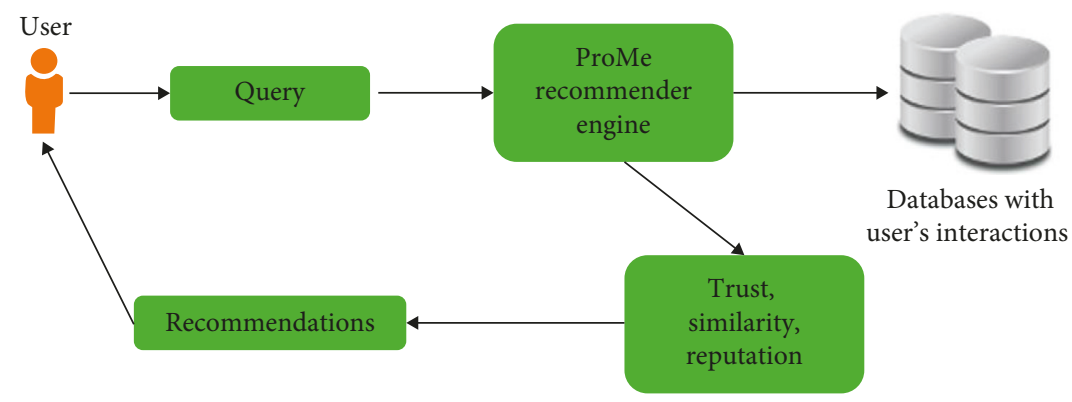

Figure 3: ProMe recommendation system.

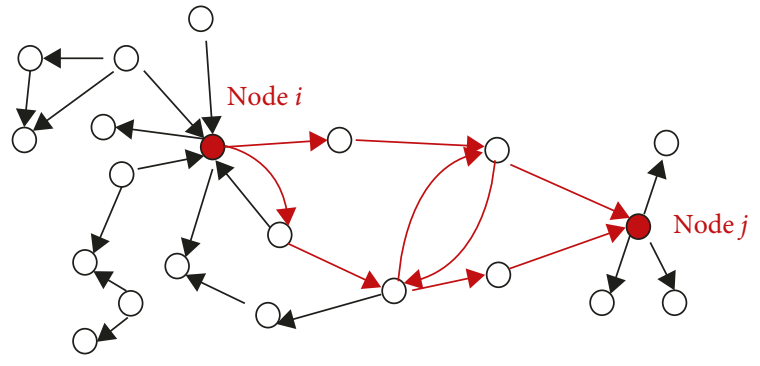

Figure 4: The model of ProMe recommendation engine.

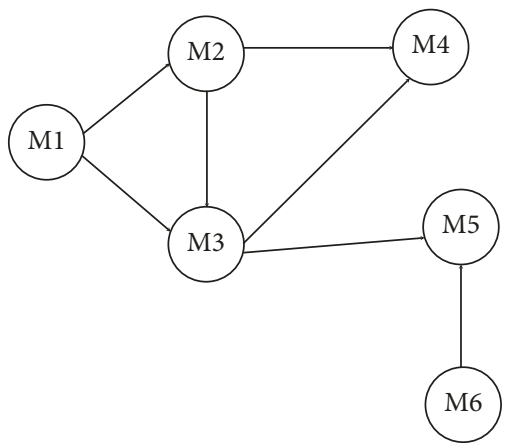

Figure 5: A trust network with no edge weights.

neighbours of mentor M1. Among all the agents except M1's neighbours M2 and M3, M4 is the most possible candidate because it is connected by two neighbours of M1.

Figure 6 presents an example of a trust network (TN2), which shares the same topology as TN1 except TN2 has trust values (rather than 1) at its nodes (edges). Unlike the result in Figure 5, although M5 has fewer connections with M1's neighbours than M4, M5 has the highest similarity score because the trust value of its only connection is much stronger than the trust values of M4's connections. Note that M3 (not considered as a recommendation because it is already a neighbour of M1) also has a high similarity score because it is connected by M2 (M1's neighbour) with a high trust value.

5.1. Mining and Machine Learning Aspects. In the machine learning field, complexity and diversity can be handled using the "Black Box" principle. Based on this principle every machine learning method is expected to fit a simple mold.

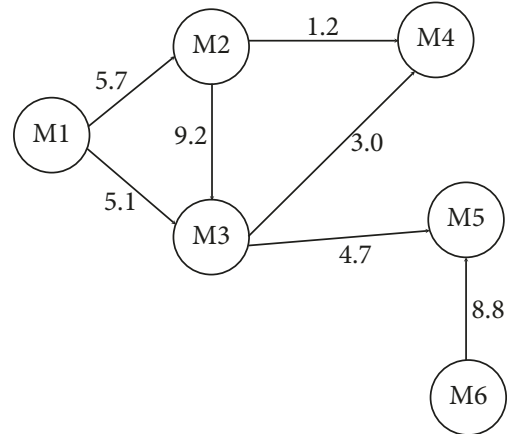

FIGURE 6: A trust network where edge weights represent trust values.

The ProMe recommendation engine/component will be responsible to gather any data coming out of the queries and constructing the actual dataset to be used for training and testing the machine learning algorithm. The recommendation engine/component supports the following three procedures:

(1) To establish a safe connection with the actual databases

(2) To query the databases and receive the data

(3) To save the data in a proper, for the machine learning algorithm, format

Despite the fact that each algorithm is different from the others, the following five steps should be followed throughout the development and application phase:

(1) Data collection: data collection refers to the actual method to be followed in order to collect the data. Data can be collected with the use of APIs, RSS feed, through (sensor) devices that can collect and transmit the data, etc.

(2) Data preparation: data preparation is one of the most important steps. Data should be in a suitable format to be fed to an algorithm. Algorithms may need the provided features to follow a specific format. Some work only with features and/or variables in string format, while others ask for data to be integers.

(3) Training the algorithm: in the training the algorithm step, we provide the algorithm with the data from the previous step, and as an outcome, we expect to gain a 
much deeper and extended insight into the provided data. In the case of unsupervised learning and since we do not have a specific value to target, no training step takes place.

(4) Testing the algorithm: In the testing the algorithm, the evaluation of the algorithm is taking place. When we are referring to supervised learning, someone usually has known values to evaluate the algorithm. For example, ground truth data to be checked against the performance of the algorithm. Support and confidence should be used in unsupervised learning, in order to check if it is successful or not.

(5) Usage: in this final step, we check the algorithm's implementation in practice. Of course, there is always the need to continuously check if the aforementioned four steps are delivering as expected.

5.2. Recommendation System Testing. The recommendation system is the system responsible for the three from the end steps in the previously described sequence of actions (steps 3 to 5). The recommendation system is providing the whole framework with the needed functionality in order to (i) receive the data, (ii) to feed the machine learning algorithm, and (iii) to provide a better insight for them. The ultimate target for a machine learning algorithm is to spot any interesting relationships when working with the dataset. But how do we quantify interesting relationships? First, we should find a frequent itemset, and second, we should measure any interesting relationships in association rules.

Algorithms, like Apriori [24], can be used to enhance the recommendation system with extra association rules, thus providing an even more robust system. Apriori is based on the principle that if an item is not frequent, that automatically suggests that supersets containing that specific item are not frequent too (Algorithm 1). What plays a vital role on how to test and measure is the user's population. The bigger the dataset, the bigger the quality which can be achieved.

\section{Conclusions}

The basic scope of the ProMe project was to design and eventually bring to life a platform which will be in position to provide the needed tools so as mentoring and of course knowledge sharing among older and younger generations to be feasible. Another target of the framework is to assist older adults throughout the transition phase, from full-time employment to retirement. Thus supporting their mental health and quality of life. Last but not least, to provide equal importance is the continuity in knowledge and experience passing from the older ones to the younger generation. Results till now show that users consider the platform useful and easy to use.

ProMe is in position to provide accurate (to the platform user) recommendations. This is possible by implementing algorithms to adequately cope with the vast amount of data coming from Internet, by implementing customized algorithms for analyzing the incoming data, and by designing and implementing the needed for the user behavior analysis
(1) $C_{k}$ : Candidate itemset of size $\mathrm{k}$

(2) $L_{k}$ : frequent itemset of size $\mathrm{k}$

(3) $L_{l}=\{$ frequent items $\}$;

(4) for $\left(k=1 ; L_{\mathrm{k}} !=\varnothing ; k++\right)$ do begin

(5) $\quad C_{k+l}=$ Candidate generated form $L_{\mathrm{k}}$;

(6) for each transaction $t$ in database do

(7) increment the count of all candidates in

(8) $\quad C_{k+l}$ that are contained in $t$

(9) $\quad L_{k+l}=$ candidates in $C_{k+l}$ with min_support

(10) end

(11) return $\cup_{k} L_{k}$;

Algorithm 1: The Apriori algorithm.

and recommendation algorithm. Initially a user is asking for possible recommendations with the use of a query, which is then passed to the actual recommender component. Based on historical user activities, the recommender component "calculate" the following ingredients: (i) trust, (ii) reputation, and (iii) similarity. Based on the above "calculations" the ProMe platform is in position to provide the end user with the needed recommendations.

ProMe is now a working online service platform for mentoring, which focuses on intergenerational cooperation. It enables adults after retirement to pass their their professional formal and tacit knowledge to younger adults, who can benefit from this valuable asset, e.g., when starting their own career. Mentoring is a win-win situation for all parties involved. The mentor has the opportunity to help changing another person's life by sharing knowledge and experience. The mentee can be sure to be supported in walking towards a self-defined goal by someone experienced and professional. The ProMe platform provides a matching system that connects mentors/ mentees accordingly to their needs and expectations. A variety of communication and collaboration tools are offered that support mentor/mentee to successfully work together.

\section{Data Availability}

The data are coming from an insurance company in Greece, which was really happy to assist in the validation of the proposed architecture/platform. Unfortunately, the data cannot be available due to their nature. The data used to support the findings of this study are currently under embargo, while the research findings are commercialized. Requests for data, (6/12 months) after publication of this article, will be considered by the corresponding author.

\section{Conflicts of Interest}

The authors declare that there are no conflicts of interest regarding the publication of this paper.

\section{Acknowledgments}

This research was enabled by the ProMe project. The financial support by the AAL JP and the support of all involved parties in the project are gratefully acknowledged. 


\section{References}

[1] ProMe website, 2018, http://pro-me.eu/.

[2] R. Schaap, A. de Wind, P. Coenen, K. Proper, and C. Boot, "The effects of exit from work on health across different socioeconomic groups: a systematic literature review," Journal of Social Science \& Medicine, vol. 198, pp. 36-45, 2018.

[3] P. Eibih, "Understanding the effect of retirement on health: mechanisms and heterogeneity," Journal of Health Economics, vol. 43, pp. 1-12, 2015.

[4] H. Schmitch, "Why are the unemployed in worse health? The causal effect of unemployment on health," Journal of Labour Economics, vol. 18, no. 1, pp. 71-78, 2011.

[5] M. Bertoni, G. Brunello, and G. Mazzarella, "Does postponing minimum retirement age improve healthy behaviors before retirement? Evidence from middle-aged Italian workers," Journal of Health Economics, vol. 58, pp. 215-227, 2018.

[6] T. Müller and M. Shaikh, "Your retirement and my health behavior: evidence on retirement externalities from a fuzzy regression discontinuity design," Journal of Health Economics, vol. 57, pp. 45-59, 2018.

[7] O. Shai, "Is retirement good for men's health? Evidence using a change in the retirement age in Israel," Journal of Health Economics, vol. 57, pp. 15-30, 2018.

[8] H. T. M. Nguyen, "Theories of mentoring," in Models of Mentoring in Language teacher Education, Springer Nature, Basel, Switzerland, 2017.

[9] T. Kerry and A. S. Mayes, Issues in Mentoring, The Open University, Milton Keynes, UK, 2014, ISBN: 9781136159343.

[10] D. Rousseau, "Psychological contracts in organizations," in Understanding Written and Unwritten Agreements, Sage Publications, Thousand Oaks, CA, USA, 1995.

[11] D. L. Haggard and D. B. Turban, "The mentoring relationship as a context for psychological contract development," Journal of Applied Social Psychology, vol. 42, no. 8, pp. 1904-1931, 2012.

[12] D. M. Rousseau, "Psychological and implied contracts in organizations," Employee Responsibilities and Rights Journal, vol. 2, no. 2, pp. 121-139, 1989.

[13] J. P. Kotter, "The psychological contract: managing the joining-up process," California Management Review Spring, vol. 15, no. 3, pp. 91-99, 1973.

[14] Horsesmouth Website, 2018, http://www.horsesmouth.co.uk/ index.publisha.

[15] Senior Engage Website, 2018, http://seniorengage.eu/.

[16] Aware Website, 2018, http://aware.ibv.org/en/home/.

[17] E-Mentoring Website, 2018, http://www.e-mentoring.org/.

[18] Hear Me Website, 2018, http://www.viauc.com/projects/.

[19] Horizons Unlimited Website, 2018, http://horizonsunlimited. com.au/.

[20] Mentor Website, 2018, http://www.mentoring.org/.

[21] Mentor Net Website, 2018, http://www.mentornet.net/.

[22] R. T. Fielding and R. N. Taylor, "Principled design of the modern web architecture," ACM Transactions on Internet Technology (TOIT), vol. 2, no. 2, pp. 115-150, 2002.

[23] C. Chrysoulas and M. Fasli, "Building an adaptive E-learning system," in Proceedings of 9th International Conference on Computer Supported Education, Porto, Portugal, April, 2017.

[24] R. Agrawal and R. Srikant, "Fast algorithms for mining association rules," in Proceedings 20th International Conference on Very Large Data Bases, VLDB, pp. 487-499, Santiago de Chile, Chile, September 1994. 


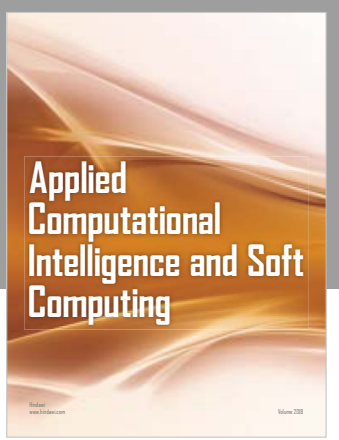

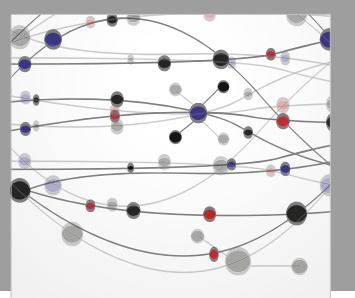

The Scientific World Journal
Submit your manuscripts at

Computing
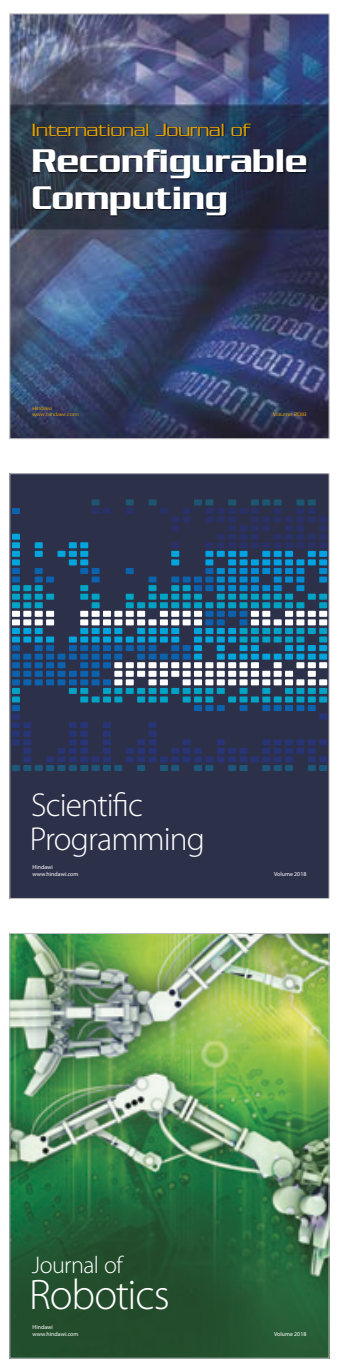

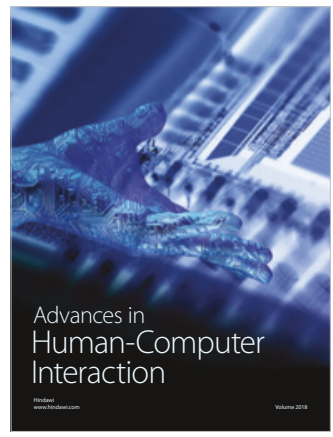

Human-Compute

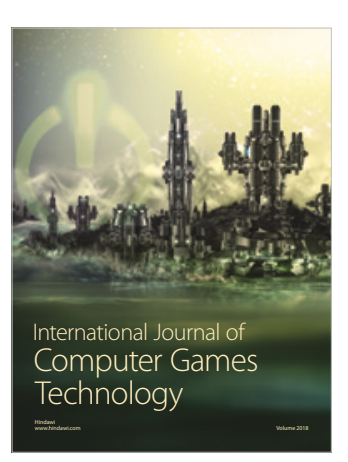

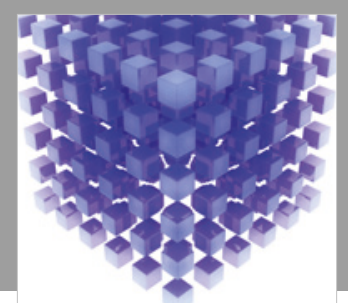

Mathematical Problems in Engineering

\section{Engincering}
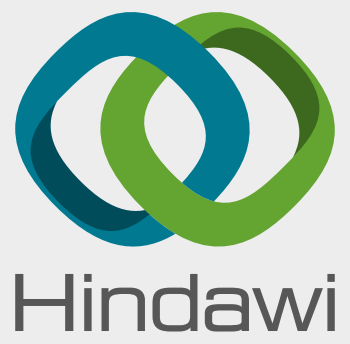

www.hindawi.com
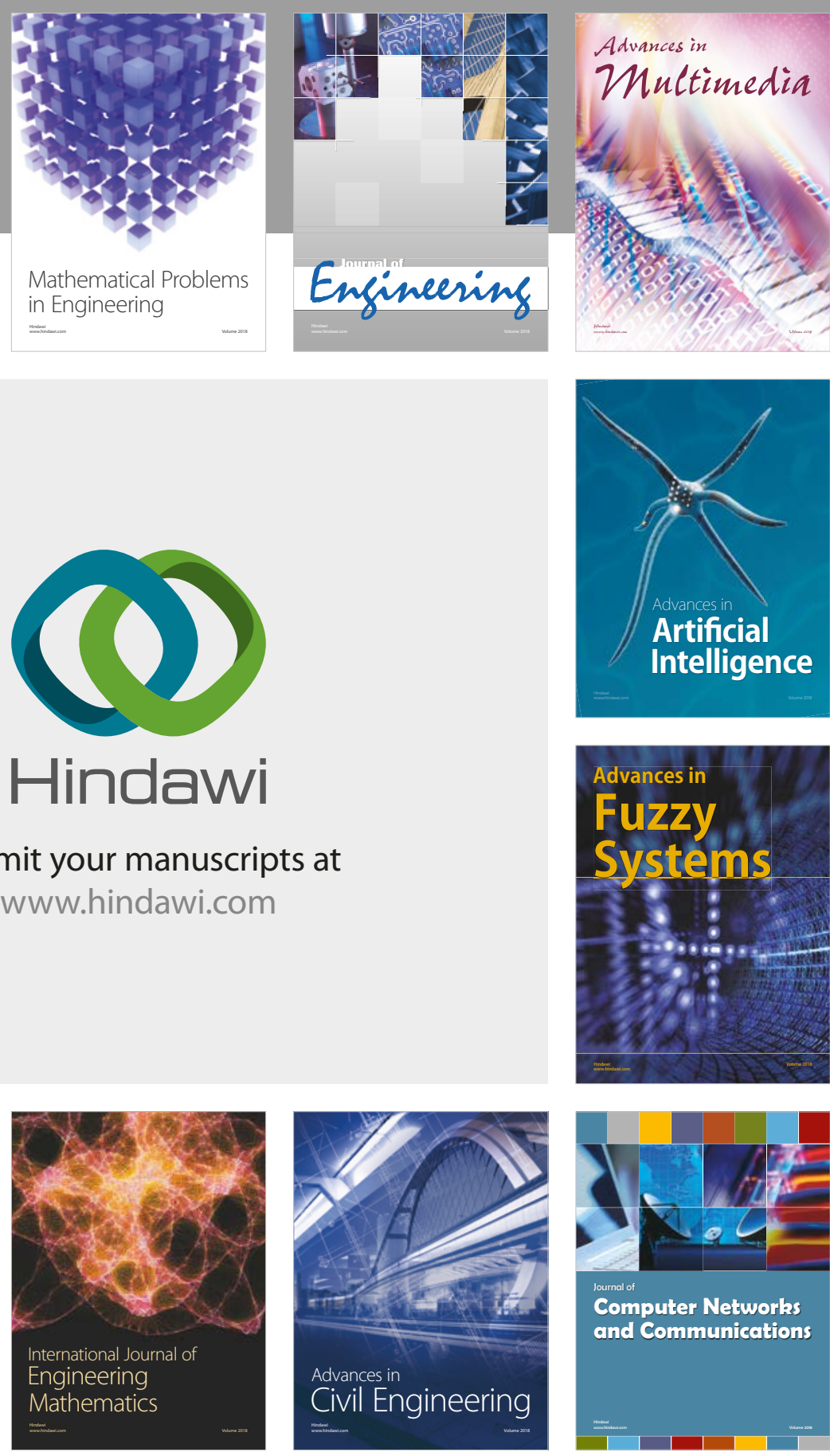

Computer Networks and Communications

Multimedia
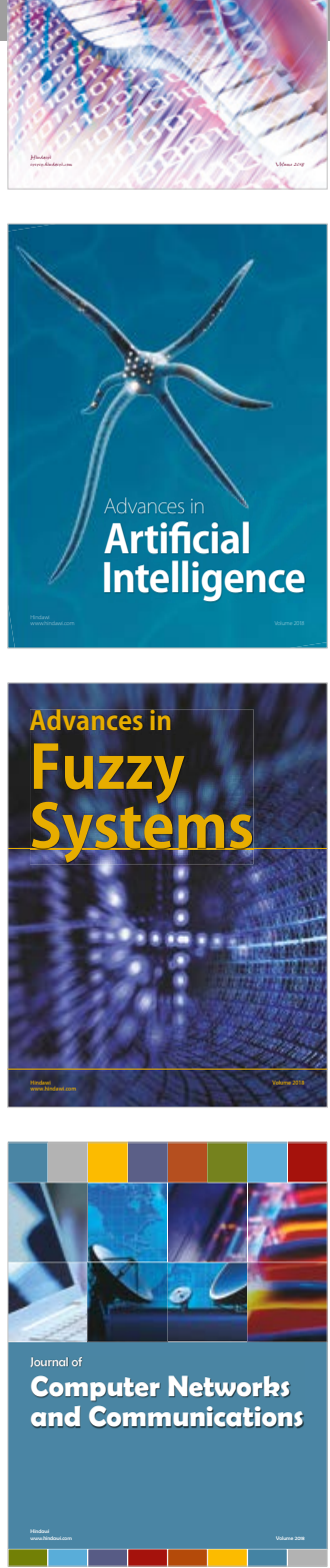

Advances in

Modelling \&

Simulation

in Engineering

interaction

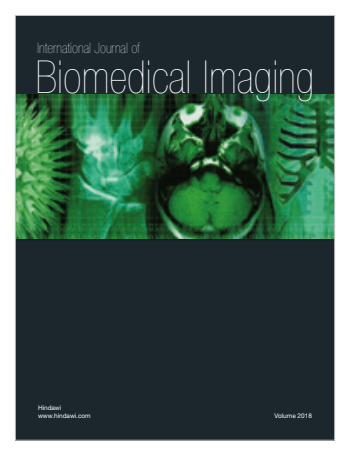

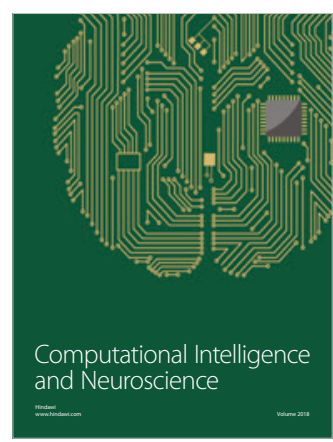

